\section{Disección coronaria espontánea en paciente trasplantada de corazón}

\author{
VÍCTOR ROSSEL ${ }^{1,2}$, DANIEL SAN MARTÍN, \\ JONGSUNG LIM ${ }^{1}$, RICARDO RAMÍREZ ${ }^{3}$, \\ FRANCESCA GAJARDO $^{1, \mathrm{a}}$, JORGE SANDOVAL ${ }^{1,2}$
}

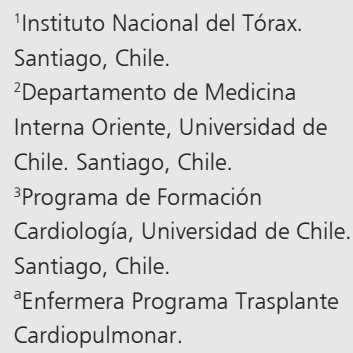

Los autores declaran no tener conflictos de interés.

Trabajo no recibió financiamiento

Recibido el 18 de agosto de 2020, aceptado el 19 de enero de 2021.

Correspondencia a:

Víctor Rossel

Avenida Salvador 486. Santiago,

Chile.

vrossel@uchile.cl follow-up coronary angiography three years after transplantation, supplemented with optical coherence tomography. A percutaneous coronary revascularization of the involved artery was performed, with good immediate results and at one year of follow-up.

(Rev Med Chile 2021; 149: 469-471) Heart.

Key words: Coronary artery dissection, Spontaneous; Transplantation,

\section{L} a disección coronaria espontánea (DCE) es definida como una separación espontánea $\checkmark$ de las capas de la pared arterial coronaria, provocada por un desgarro intimal o una hemorragia intramural espontánea, que puede conducir a isquemia miocárdica. Es una causa no frecuente de síndrome coronario agudo (SCA) que afecta predominantemente a mujeres jóvenes, con una serie de condiciones predisponentes y factores gatillantes ${ }^{1}$. La arteria coronaria más comprometida es la descendente anterior $(\mathrm{ADA})^{2,3}$. En pacientes trasplantados la DCE es una condición extremadamente rara, habiéndose descrito sólo en 3 pacientes ( 2 trasplantados renales y 1 hepático), en quienes se plantea una posible relación con el uso de anticalcineuríni$\cos ^{4,5}$. El objetivo de este trabajo es comunicar el primer caso de DCE en una receptora de trasplante cardíaco (TxC).

\section{Presentación del caso}

Paciente de sexo femenino, portadora de enfermedad de Ebstein y comunicación interauricular (CIA) amplia con hipertensión pulmonar. Por insuficiencia cardíaca derecha aguda severa requirió instalación de ECMO (del inglés Extracorporeal Membrane Oxigenation). Se programó cierre de la CIA saliendo de pabellón con asistencia ventricular derecha Centrimag. Al no mostrar recuperación, se enlistó y tras 230 días se efectuó TxC ortotópico (34 años), con crossmatch prospectivo por vPRA (virtual Panel Reactive Antibodies) de $88 \%$ e inducción con basiliximab. Al tercer mes post-trasplante presentó rechazo celular agudo moderado que requirió metilprednisolona bolus y ajuste de inmunosupresores. Continuó tratamiento con prednisona, tacrolimus y ácido micofenólico, sin demostrar nuevos episodios de rechazo y con adecuada función del injerto. 


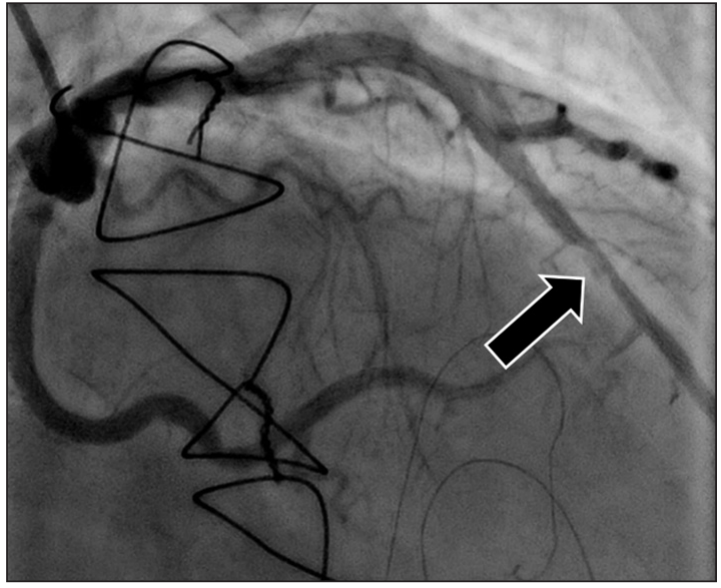

Figura 1. Coronariografía, proyección oblicua derecha craneal, con aclaramiento focal en zona media, imagen lineal y retención de medio de contraste (flecha negra) sugerente de disección coronaria tipo 1, arteria descendente anterior, segmento medio.

A los 3 años post-trasplante (37 años) acudió a coronariografía de seguimiento, recibía como tratamiento: prednisona $5 \mathrm{mg} /$ día, ácido micofenólico $360 \mathrm{mg}$ cada $12 \mathrm{~h}$, tacrolimus 1 mg cada $12 \mathrm{~h}$, (niveles plasmáticos 7,3 ng/dL), ácido acetilsalicílico $100 \mathrm{mg} /$ día y atorvastatina $20 \mathrm{mg} /$ día.

Previo al procedimiento refería disnea de esfuerzos, sin dolor torácico. La coronariografía mostró disección coronaria tipo 1, en el segmento medio de la ADA (figura 1; video 1, material suplementario), con flujo TIMI 3, sin otras lesiones. Se realizó tomografía de coherencia óptica (OCT) que confirmó la disección (Figura 2 ; video 2, material suplementario), sin engrosamiento intimal. Los biomarcadores no mostraron alteraciones. La ecocardiografía evidenció una fracción de eyección de 65\%, sin defectos segmentarios de motilidad ni insuficiencias valvulares. Se decidió intervención coronaria percutánea (ICP) e implante de stent medicado. La biopsia endomiocárdica simultánea no mostró signos de rechazo. Se mantuvo con ácido acetilsalicílico y clopidogrel por 6 meses. La coronariografía un año post-procedimiento reveló permeabilidad del stent, sin aparición de nuevas lesiones. Se obtuvo consentimiento del paciente para publicación del caso.

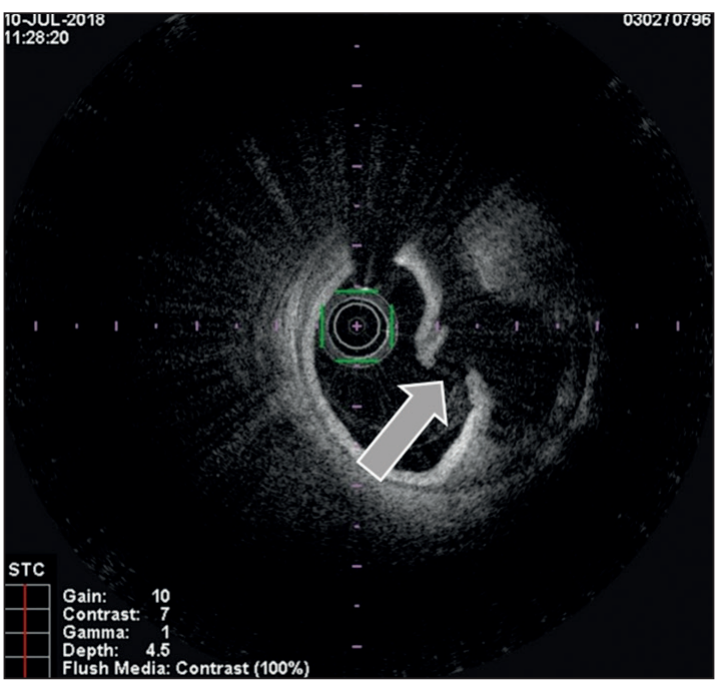

Figura 2. Tomografía de coherencia óptica de la arteria descendente anterior con separación y rotura de la íntima (flecha gris) y llene del falso lumen.

\section{Discusión}

Existen varias condiciones que predisponen a la DCE, entre ellas: enfermedades del tejido conectivo, inflamatorias crónicas y el período postparto, siendo la más frecuente la displasia fibromuscular ${ }^{1}$. Los inhibidores de la calcineurina (ICN), uno de los pilares del tratamiento inmunosupresor, exhiben una variedad de efectos secundarios sobre la vasculatura, tales como: vasoconstricción aguda; disfunción endotelial, con aumento de la liberación de sustancias vasoconstrictoras; aumento del tono simpático, producción de radicales libres derivados del oxígeno y un estado proinflamatorio $^{6}$. Nuestra paciente recibía el ICN tacrolimus y, como ha sido postulado previamente ${ }^{4,5}$, no es posible descartar que su uso crónico haya contribuido, a través de estos efectos, a desarrollar la DCE.

Otra explicación que se planteó en este caso fue la posibilidad de un rechazo humoral, por el alto grado de sensibilización de la paciente, y que la DCE representara una manifestación vascular del rechazo, sin embargo, la biopsia endomiocárdica no mostró hallazgos sugerentes.

La presentación clínica de la DCE va desde el SCA a la muerte súbita. En este aspecto es necesario recordar que la cardiectomía del corazón donado interrumpe las fibras aferentes y eferentes, 
las que no son restauradas tras el implante del injerto, creando un estado de denervación cardíaca, que provoca entre otros, la ausencia de angina en el receptor, lo que podría explicar la presentación clínica en esta paciente.

En cuanto al diagnóstico de la DCE, el examen de elección es la coronariografía, complementada con ultrasonido coronario u $\mathrm{OCT}^{2,3}$, que muestran el rasgo de disección o el hematoma intramural. El tratamiento en el escenario del SCA es la ICP, aunque en ocasiones, cuando el flujo coronario está conservado y la situación clínica es estable, puede optarse por terapia farmacológica exclusiva ${ }^{3}$.

En esta paciente se decidió ICP, a pesar de que la DCE no afectaba el flujo coronario, por las consecuencias negativas que pudiese tener un evento coronario sobre la función del injerto, ya que en muchas ocasiones el diagnóstico de infarto es efectuado en forma retrospectiva por reaparición de falla cardíaca o a través del ecocardiograma.

\section{Limitaciones}

Si bien es cierto no hay antecedentes clínicos de algunas de las condiciones predisponentes descritas, no se efectuó un estudio dirigido a través de imágenes de angio-tomografía axial computada o angio-resonancia para descartarlas.

\section{Refreencias}

1. Saw J, Aymong E, Sediak T, Buller CE, Starovoytov A, et al. Spontaneous coronary artery dissection: association with predisposing arteriopathies and precipitating stressors and cardiovascular outcomes. Circ Cardiovasc Interv 2014; 7: 645-55.

2. Tweet MS, Kok SN, Hayes SN. Spontaneous coronary artery dissection in women: What is known and What is yet to be understood. Clin Cardiol 2018; 41: 203-10.

3. Vandamme M, De Backer J, De Backer T, Drieghe B, Devos D, Gevaert S, et al. The spectrum of spontaneous coronary artery dissection: illustrated review of the literatura. Acta Cardiol 2017; 72: 599-609.

4. Tsimikas S, Giordano FJ, Tarazi RY, Beyer RW. Spontaneous coronary artery dissection in patients with renal transplantation. J Invasive Cardiol 1999; 11: 316-21.

5. Mallon DH, McKenzie D, Dayer M. A spontaneous coronary arterial dissection associated with a calcineurin inhibitor. BMJ Case Rep 2012; 2012. pii: bcr2012006414.

6. Lamas S. Cellular mechanisms of vascular injury mediated by calcineurin inhibitors. Kidney Int 2005; 68: 898-907. 